\title{
Uso da plataforma Khan Academy no laboratório de informática em uma escola da rede municipal de Santos: incentivo e motivação ao aprendizado de matemática
}

Using the Khan Academy platform in the computer lab in a municipal school of Santos: incentive and motivation to learning Mathematics

\section{Uso de la plataforma Khan Academy en el laboratorio} de informática en una escuela de la red municipal de Santos: incentivo y motivación al aprendizaje de matemáticas

Cláudia Regina Bazoli Silva Villar

Universidade Metropolitana de Santos (Unimes), Santos/SP - Brasil

Thiago Simão Gomes

Universidade Metropolitana de Santos (Unimes), Santos/SP - Brasil

\section{Resumo}

O trabalho aqui apresentado trata da utilização da plataforma Khan Academy, no laboratório de informática de uma escola da rede municipal de ensino de Santos/SP, com o objetivo de incentivar e promover contribuições ao aprendizado de matemática. Entendemos que oportunizar o manuseio de recursos tecnológicos, além de cooperar para o aprendizado do aluno, poderá minimizar significativamente suas dificuldades matemáticas. Quanto ao professor de matemática, ao utilizar a plataforma Khan Academy, disporá de ferramenta facilitadora para diagnosticar e promover intervenção e reorientação na aprendizagem de seus discentes, colaborando para o planejamento de suas aulas e práticas pedagógicas.

Palavras-chaves: Khan Academy, Matemática, Aprendizagem, Planejamento, Práticas pedagógicas 


\begin{abstract}
This work is about using the Khan Academy platform in the computer lab in a municipal school of Santos, with the purpose of encouraging and promoting contributions to the learning of Mathematics. We understand that opportuning the handling of technological resources, besides cooperating with the student's learning, can significantly minimize their mathematical difficulties. For the Mathematics teachers, when using the Khan Academy platform he will have a facilitating tool to diagnose and promote intervention and reorientation in the learning of their students, collaborating with the planning of their classes and pedagogical practices.
\end{abstract}

Keywords: Khan Academy, Mathematics; Learning; Planning; Pedagogical practices

\title{
Resumen
}

El trabajo aquí presentado trata del uso de la plataforma Khan Academy, en el laboratorio de informática de una escuela de la red municipal de enseñanza de Santos / SP, con el objetivo de incentivar y promover contribuciones al aprendizaje de matemáticas. Entendemos que propiciar el manejo de recursos tecnológicos, además de cooperar para el aprendizaje del alumno, podrá minimizar significativamente sus dificultades matemáticas. En cuanto al profesor de matemáticas, al utilizar la plataforma Khan Academy, dispondrá de herramienta facilitadora para diagnosticar y promover intervención y reorientación en el aprendizaje de sus alumnos, colaborando para la planificación de sus clases y prácticas pedagógicas.

Palabras claves: Khan Academy, Matemáticas, Aprendizaje, Planificación, Prácticas pedagógicas

\section{Introdução}

A proposta deste trabalho é a de verificar o uso da plataforma Khan Academy como ferramenta de suporte, por ser considerada facilitadora do aprendizado de matemática, por meio das aulas ministradas no laboratório de informática, onde se realiza a parceria entre professor de matemática e o Professor Orientador de Informática Educativa - POIE1.

\footnotetext{
${ }^{1}$ A função POIE foi criada para professores da rede municipal de Santos ministrarem aulas no laboratório de informática. A cidade de Santos, pioneira nesse projeto, conseguiu avanços e resultados educacionais significativos e de grande sucesso. Sucesso esse, reconhecido por inúmeras outras redes educacionais que espelham o seu processo de inclusão digital nesse pioneirismo, conforme divulgado no site Portal da Educação Santos, disponível em: $<$ http://www.portal.santos.sp.gov.br/seduc/page.php?245site>.
}

Revista Educação Online, Rio de Janeiro, n. 25, mai-ago 2017, p. 40-62 
Khan Academy é uma plataforma norte-americana, on-line, intuitiva e gratuita, com videoaulas e exercícios que propiciam o aprendizado matemático a qualquer pessoa, de maneira personalizada, demonstrando habilidades dominadas e as que necessitam de prática.

Disponibilizamos a plataforma no laboratório de informática, para contribuir com o processo de aprendizagem do educando em relação aos conteúdos matemáticos. Com a sua utilização, buscamos verificar se ocorreram avanços no aprendizado dessa disciplina, por meio das notas disponibilizadas no Sistema Integrado de Gestão Escolar (Siges).

Em 2014, as videoaulas e exercícios da Khan Academy passaram a ser traduzidas para o português pela Fundação Lemann, que também oferece um programa gratuito às escolas públicas, propiciando a formação continuada de professores, não só para que utilizem a plataforma em seu dia a dia com seus alunos, mas para que compartilhem esse conhecimento com outros educadores, conforme divulgado no site da Fundação Lemann².

Apesar de as escolas se apropriarem cada vez mais de recursos tecnológicos, ainda hoje, é um desafio para professores e a instituição de ensino se adaptarem a essa integração tecnológica, pois a prática pedagógica não promove essa integração. Não há consistência entre as TIC (Tecnologia da Informação e Comunicação) e o currículo escolar. Por esse motivo, faz-se necessária a revisão do currículo e do plano político pedagógico, o que possibilitará aos educadores explorarem atividades nas quais os recursos tecnológicos se integrem à realidade do aluno, promovendo uma aprendizagem mais ativa (MENEGAIS, 2015).

Enquanto essa ação não é efetivada, as secretarias da educação e as escolas buscam meios para minimizarem os problemas em relação à defasagem no aprendizado dos alunos, principalmente, no que diz respeito à defasagem matemática.

${ }^{2}$ Site: <http://www.fundacaolemann.org.br/khan-academy/>

Revista Educação Online, Rio de Janeiro, n. 25, mai-ago 2017, p. 40-62 
Nesse sentido, a rede municipal de ensino de Santos, por meio da Secretaria da Educação - Seduc, firmou parceria com a Fundação Lemann, em 2014, e implantou o Projeto Piloto para uso da plataforma Khan Academy, no laboratório de informática, em quatro escolas da rede, com a expectativa de contribuir para o aprendizado dos alunos no ensino de matemática. De acordo com Castells (2003 apud MENEGAIS, 2015) "o uso das tecnologias digitais, integradas às práticas pedagógicas pode ser um dos elementos capazes de melhorar a aprendizagem de matemática na atual Sociedade em Rede" (p. 34).

Os professores de matemática e informática participaram de duas formações continuadas, realizadas pela Fundação Lemann, em 2014, o que possibilitou a familiarização com a plataforma. Nesse mesmo ano, durante o período de implantação, a Fundação deu suporte ao acompanhamento dos relatórios fornecidos pela plataforma. Através deles, foi possível verificar o acesso e o desempenho dos alunos, em relação às habilidades dominadas ou com dificuldades, e as que precisavam praticar, possibilitando ao professor acompanhar e ter um diagnóstico imediato sobre as dificuldades dos alunos, bem como o desenvolvimento e domínio de habilidades.

O presente estudo, portanto, tem como objetivo:

- Avaliar, por meio do levantamento de notas bimestrais da disciplina de matemática, se o uso da plataforma Khan Academy contribuiu de maneira efetiva para a melhora do desempenho matemático de alunos do sexto ano do ensino fundamental, no período de 2013 a 2015;

- Avaliar, por meio de questionário realizado com os alunos que em 2016 cursaram o sétimo ano, e que fizeram uso da plataforma em 2015, de que maneira a plataforma teve contribuição efetiva para seu aprendizado matemático;

- $\quad$ Avaliar, por meio de questionário realizado com professores de matemática que participaram do projeto durante o ano de 2015, se o uso da plataforma contribuiu como ferramenta facilitadora para a prática pedagógica em sala de aula.

Revista Educação Online, Rio de Janeiro, n. 25, mai-ago 2017, p. 40-62 
Diante dessas considerações, discute-se inicialmente como a plataforma Khan Academy contribui como ferramenta facilitadora e motivadora ao ensino e aprendizagem de matemática. A seção 2 apresenta a análise e discussão de dados e é dividida em dois tópicos. O primeiro apresenta a análise feita em relação ao levantamento de notas obtidas, por meio do Siges, para o componente curricular de matemática envolvendo o período de 2013 a 2015, com alunos do sexto ano do ensino fundamental. O segundo tópico apresenta a análise dos questionários aplicados aos alunos e professores de matemática que fizeram uso da plataforma no laboratório de informática, durante o ano de 2015. Na seção 3, apresentam-se algumas considerações em relação ao uso da plataforma Khan Academy e sua aplicação no contexto escolar.

\section{Khan Academy, ferramenta facilitadora do ensino e aprendizagem de matemática}

A plataforma Khan Academy tem por objetivo oferecer aprendizado personalizado e adaptativo, ou seja, aprender sobre o usuário para depois ensiná-lo. Permite ao professor monitorar e identificar o progresso de seus alunos. Toda a interação dos estudantes com seus recursos geram dados automaticamente, transformados em relatórios simples e objetivos, que possibilitam ao professor gerenciar o progresso e acompanhar de perto o desempenho da aprendizagem de cada aluno, tornando-a uma poderosa ferramenta pedagógica.

De acordo com Coll e Monereo (2010), "o papel mais importante do professor em ambientes virtuais, entre os que identificamos, é o de mediador, entendido como alguém que proporciona auxílios educacionais ajustados à atividade construtiva do aluno, utilizando as TIC para fazer isso" (p. 129).

Nesse sentido, entendemos que, para que ocorra a construção do conhecimento por parte do aluno com uso de recursos tecnológicos, é necessário que o professor esteja envolvido, atuando como orientador e mediador que contribui para essa construção. Para isso, o professor deve receber formação, a fim de se apropriar dos recursos oferecidos pela Internet.

Revista Educação Online, Rio de Janeiro, n. 25, mai-ago 2017, p. 40-62 
No caso desta pesquisa especificamente, ele deve estar preparado para compreender os recursos e ferramentas oferecidos na plataforma Khan Academy, compreender e fazer a leitura dos relatórios, que podem vir a contribuir para o processo de transformação em sua maneira de enxergar cada aluno e o coletivo e, com isso, transformar sua metodologia e modo de ensinar.

Para Sanchez (2004, p.174-175), as dificuldades de aprendizagem em matemática podem ocorrer por diversos motivos, dentre eles, dificuldades originadas no ensino inadequado ou insuficiente, por conteúdos que não se adequam às necessidades e ao nível de desenvolvimento do aluno, impossibilitando que o aluno aprenda dentro do seu próprio ritmo; ainda aponta a metodologia de ensino, que pode ser muito pouco motivadora e muito pouco eficaz.

Entendemos que o professor, ao receber formação para conhecer os recursos disponibilizados na plataforma e se familiarizar com esses recursos, deve apresentar condições de acompanhar o desenvolvimento de seus alunos, intervindo em todas as dificuldades que possam apresentar, e pode fazer isso de forma que o aluno se sinta motivado a aprender.

Dessa forma, ao entender o conhecimento como algo que é ativamente construído pelos sujeitos, de forma colaborativa e cooperativa, abordamos uma perspectiva piagetiana (PIAGET, 1973, p. 105), na qual colaborar se relaciona às ações realizadas pelos parceiros na direção de um objetivo comum, embora essas ações sejam feitas isoladamente. Cooperar, por sua vez, é "operar em comum, isto é, ajustar por meio de novas operações (qualitativas ou métricas) de correspondência, reciprocidade ou complementaridade, as operações executadas por cada um dos parceiros" (MENEGAIS, 2015, p. 77).

Para Kenski (2015), "A forma de utilização de alguma inovação precisa ser informada e aprendida, para aprender a utilizar um computador, precisamos buscar informações, realizar cursos, pedir ajuda aos mais experientes" (p. 4344). Essas novas descobertas, ao serem colocadas em prática, reorientam nossas relações, valores e comportamentos.

Revista Educação Online, Rio de Janeiro, n. 25, mai-ago 2017, p. 40-62 
Com o advento da Internet, presente em nossas vidas, Moran (2000) alega que há necessidade de modificarmos nossa forma de ensinar e aprender, o que depende do educador e do educando num processo compartilhado. "O educador coordena, sensibiliza, organiza o processo, que vai sendo construído em conjunto com as habilidades e tecnologias possíveis a cada grupo, de forma participativa" (p. 62). Esse processo se baseia na confiança, interação, troca e estímulo, sempre com ênfase no incentivo, facilitando todo o processo de organização da aprendizagem. A Internet nos proporciona modificar nossa forma de ensinar e aprender. Ao se apropriar dessas inovações, o professor amplia opções que possibilitam formas diferenciadas de contribuir para a construção do conhecimento do aluno, podendo inclusive avaliar esse aluno com técnicas que vão além de provas tradicionais, que, muitas vezes, causam tensão e, dependendo do resultado, agravam um sentimento de baixa autoestima e não promovem o conhecimento necessário ao aluno. Com isso, entendemos que devemos repensar também a questão da avaliação, pois, de acordo com Luckesi (2005),

O ato de examinar tem como função a classificação do educando, minimamente, em "aprovado ou reprovado"; no máximo, em uma escala mais ampla de graus, tais como as notas, que variam de 0 (zero) a 10 (dez) ou como é uma escala de conceitos, que pode conter cinco ou mais graus. Ao ato de examinar, não importa que todos os estudantes aprendam com qualidade, mas somente a demonstração e classificação dos que aprenderam e dos que não aprenderam. E isso basta. Deste modo, o ato de examinar está voltado para o passado, na medida em que deseja saber do educando somente o que ele já aprendeu; o que ele não aprendeu não traz nenhum interesse. Diversamente, o ato de avaliar tem como função investigar a qualidade do desempenho dos estudantes, tendo em vista proceder a uma intervenção para a melhoria dos resultados, caso seja necessária. Assim, a avaliação é diagnóstica. Como investigação sobre o desempenho escolar dos estudantes, ela gera um conhecimento sobre o seu estado de aprendizagem e, assim, tanto é importante o que ele aprendeu como o que ele ainda não aprendeu. O que já 
aprendeu está bem; mas, o que não aprendeu (e necessita de aprender, porque é essencial) indica a necessidade da intervenção de reorientação..., até que aprenda. Alguma coisa que necessita de ser aprendida, como essencial, não pode permanecer não aprendida. Tomar conhecimento somente do que 0 educando aprendeu não permite investir no processo, porém somente no produto. (p. 2)

Entendemos que muito há de ser feito para causar uma grande transformação no processo avaliativo do aluno, pois ao final do bimestre ou trimestre, importam os resultados obtidos, principalmente, em avaliações realizadas em sala de aula, e, por esse motivo, percebemos que oferecer recursos que contribuam para o aprendizado do aluno é uma forma de minimizar suas dificuldades matemáticas. Utilizar a plataforma Khan Academy e fazer o acompanhamento do aprendizado ou dificuldade do aluno são formas de diagnosticar e promover intervenção e reorientação até que se aprenda, conforme proposto por Luckesi (2005). Dessa forma, o professor de matemática tem a oportunidade de fazer uso dos recursos tecnológicos como ferramenta facilitadora para diagnóstico e planejamento de suas aulas.

\subsection{Utilização da plataforma Khan Academy no laboratório de informática}

De acordo com a proposta apresentada pela Fundação Lemann na formação inicial, a Seduc, por meio da escola e professores, deve garantir que haja a disponibilidade de duas aulas agendadas semanalmente com acompanhamento do professor de matemática, no laboratório de informática, para que professores e alunos tenham acesso à plataforma Khan Academy. Se houver incompatibilidade para o agendamento de duas aulas, uma, no mínimo, deve ser garantida e acompanhada pelo professor de matemática, e a outra durante a aula de informática. Nesse caso, os alunos acessam a plataforma com a professora de informática.

Essas aulas foram ministradas no turno das aulas, para possibilitar a presença do professor de matemática, condição essencial ao projeto, previsto no Projeto Político Pedagógico da escola.

Revista Educação Online, Rio de Janeiro, n. 25, mai-ago 2017, p. 40-62 


\subsection{Recursos oferecidos pela plataforma Khan Academy - incentivo e motivação ao ensino e aprendizado de matemática}

No Brasil, a Fundação Lemann utilizou pessoas do ramo de dublagem para a tradução dos vídeos. De acordo com Medeiros Filho e Moura (2015), uma dessas vozes, muito conhecida, é a de Wendel Bezerra, que dá voz a personagens conhecidos de desenhos animados como Goku, de Dragon Ball $Z$, Bob Esponja, de Bob Esponja, e no cinema como a de Robert Pattinson, em Crepúsculo.

Além de possibilitar o conhecimento com exercícios e aulas em vídeos, a Khan Academy, visando a tornar a aprendizagem mais atraente às crianças e adolescentes, disponibiliza como forma de recompensa a possibilidade de se adquirir pontos, denominados "pontos de energia", que são usados para que o aluno possa trocá-los pela imagem de avatares para seu perfil. Os pontos são adquiridos de acordo com sua evolução e seu desempenho na hora de realizar os exercícios. De acordo com o avatar, é possível perceber o grau de pontuação atingido.

No perfil do usuário, há estatísticas que demonstram exatamente o que foi praticado, em quanto tempo, quantos pontos foram ganhos, quais as tarefas, habilidades, medalhas e proficiências adquiridas. Também há gráficos, que mostram o tempo gasto em cada atividade praticada, podendo, assim, o professor tutor analisar se o aluno está apresentando dificuldade ou até mesmo se destacando em algum assunto. Há uma tabela, denominada grade, que apresenta todo o conteúdo referente a determinado assunto, e, dentro desse assunto, todos os exercícios, em que se tem uma visão do desempenho de cada aluno em cada atividade. Para ter acesso a essas informações, o professor precisa estar habilitado como tutor do aluno, e isso ocorre quando o cadastro é realizado pelo professor, ou quando o aluno, em seu perfil, aceita 0 professor como tutor.

O acesso ao site no Brasil se dá pelo endereço eletrônico https://pt.khanacademy.org/, podendo ser baixado também por aplicativo para tablets, celulares etc. $O$ acesso à plataforma ocorre por meio de login e senhas

Revista Educação Online, Rio de Janeiro, n. 25, mai-ago 2017, p. 40-62 
individuais. O professor tutor ao acompanhar o desempenho de todos os alunos, ao final da aula, tem acesso aos relatórios de desempenho individual. Norteado pelas observações, pode recomendar conteúdos que façam sentido a uma turma, um aluno ou um grupo de alunos, para suprir uma defasagem ou promover o avanço, segundo os objetivos pedagógicos determinados. Por meio dos relatórios, o professor sempre tem um raio-x do conhecimento de seus alunos e pode propor duplas/grupos de trabalho, inovar nas estratégias e tornar o ensino cada vez mais personalizado. Podemos dizer, então, que a epistemologia da plataforma Khan Academy "se constitui em uma iniciativa alinhada com a abordagem construtivista, embora tenha alguns aspectos alinhados com a abordagem tradicional" (TAVARES et al. 2012, p. 9).

Para a teoria construtivista, "o sujeito desenvolve suas representações de mundo e não recebe passivamente impressões causadas pelos objetos, portanto, o sujeito é considerado proativo" (PINHEIRO; LEAL; LIMA, 2015, p. 5). Assim, "o desenvolvimento mental aparecerá, em sua organização progressiva, como uma adaptação sempre mais precisa da realidade" (PIAGET, 1964, p.16). Os autores defendem ainda, baseados em Piaget, que a teoria construtivista considera que um erro corrigido pelo próprio aprendiz pode ser mais produtivo do que um acerto imediato, pois, comparando hipóteses e refletindo sobre a ação, é que se obtêm novas ideias e novos conhecimentos.

\section{Análise e discussão de dados}

\subsection{Notas no Siges - período 2013 a 2015}

Siges é uma ferramenta administrativa que informatizou as escolas municipais de Santos. Possui um software que funciona por via da Internet, para alimentação de banco de dados e informações de todas as unidades escolares, em tempo real. Seus usuários possuem senha pessoal e acesso conforme o perfil do cargo que ocupam na unidade escolar ou na administração central da Secretaria. É constituído de três módulos: alunado, atribuição de aulas e avaliação; esse último é o módulo que nos interessa. Avaliação - os

Revista Educação Online, Rio de Janeiro, n. 25, mai-ago 2017, p. 40-62 
professores registram as notas bimestrais e o resultado final no sistema, que gera documentos como boletins e atas dos resultados.

Com base nos registros realizados no período de 2013 a 2015, fizemos uma análise, para verificarmos se houve avanço em relação às notas bimestrais e finais no componente curricular de matemática, em que nota inferior a seis significa que o aluno não atingiu aprendizagem satisfatória, enquanto notas acima de seis indicam que o aprendizado é considerado satisfatório. Para essa análise, agrupamos por bimestre as notas das quatro salas pesquisadas, 6A, 6B, 6C e 6D. Verificando a média bimestral na tabela a seguir, observamos claramente um alto grau de evolução nas notas do período pesquisado. Percebemos também que o ano de 2013, período em que professores e alunos não tinham acesso à plataforma Khan Academy, as notas referentes ao conceito bimestral e final apresentavam altos índices inferiores a seis, evoluindo conforme foi ocorrendo à utilização da plataforma.

Entendemos com essa análise, que a utilização da plataforma Khan Academy no laboratório de informática trouxe contribuições significativas ao desenvolvimento cognitivo dos alunos, o que se justifica por meio das notas digitadas e registradas no sistema de notas do Siges, corroborando com Menegais, Fagundes e Sauer (2014) ao indicar que o uso de tecnologias integradas ao currículo escolar contribuem para a construção do conhecimento matemático, tornando possível minimizar as dificuldades na aprendizagem desse componente. Conforme aponta Sanchez (2004), ao elencar entre as dificuldades de ensino, dependendo da metodologia utilizada, ocorre motivação ou desmotivação, com o que Menegais (2015) concorda, ao afirmar que ambientes onde predominam práticas tradicionais de memorização como forma de se aprender e ensinar matemática, o estudante se torna sujeito passivo. Por esse motivo, torna-se importante considerar a colocação de Coll e Monereo (2010), ao citar que, dentre as competências necessárias aos professores, está a de exercer o papel de mediador, que proporciona auxílios educacionais ajustados à atividade construtiva do aluno, fazendo uso das TIC como ferramenta em ambientes virtuais. A plataforma Khan Academy possibilita essa 
construção do conhecimento, a partir da premissa que o aluno aprende dentro do seu próprio ritmo e de maneira personalizada. Dessa forma, o professor tutor, ao acompanhar o desempenho de todos os alunos, norteado pela observação e análise dos relatórios, pode recomendar conteúdos que façam sentido a seus estudantes, para suprir uma defasagem ou promover o avanço, segundo os objetivos pedagógicos determinados. Nesse sentido, constitui-se uma abordagem construtivista, em que a comparação de hipóteses e reflexões sobre as ações, promovem a possibilidade de adquirir novos conhecimentos. Para Perrenoud (2000), "Errando, reflete-se mais sobre o problema e sobre as ações usadas para resolvê-lo".

Tabela 1: Alunos com nota menor que seis - média bimestral por ano - período de 2013 a 2015

\begin{tabular}{|c|c|c|c|c|c|}
\hline \multicolumn{6}{|c|}{ Média anual 2013 - Não era utilizada a plataforma Khan Academy } \\
\hline Bimestre & $\begin{array}{l}1^{\circ} \\
\text { Bimestre }\end{array}$ & $2^{\circ}$ Bimestre & 3ำ Bimestre & $4^{\circ}$ Bimestre & $\begin{array}{l}\text { Conceito } \\
\text { Final }\end{array}$ \\
\hline $\begin{array}{l}\text { Quantidade } \\
\text { de alunos } \\
\text { com nota }<6\end{array}$ & 8 & 10 & 13 & 12 & 8 \\
\hline $\begin{array}{c}\text { Alunos } \\
\text { matriculados } \\
\text { por bimestre }\end{array}$ & 26 & 26 & 26 & 26 & 26 \\
\hline $\begin{array}{l}\% \text { de alunos } \\
\text { com nota }<6\end{array}$ & $29,75 \%$ & $39,75 \%$ & $49,50 \%$ & $48,00 \%$ & $32,50 \%$ \\
\hline \multicolumn{6}{|c|}{$\begin{array}{c}\text { Média anual } 2014 \text { - Implantação do Projeto Piloto no decorrer do ano para uso } \\
\text { da plataforma }\end{array}$} \\
\hline Bimestre & $\begin{array}{l}1 \stackrel{0}{ } \\
\text { Bimestre }\end{array}$ & $2^{\circ}$ Bimestre & 3ำ Bimestre & 4ㅇ Bimestre & $\begin{array}{l}\text { Conceito } \\
\text { Final }\end{array}$ \\
\hline $\begin{array}{l}\text { Quantidade } \\
\text { de alunos } \\
\text { com nota }<6\end{array}$ & 8 & 8 & 5 & 5 & 3 \\
\hline $\begin{array}{c}\text { Alunos } \\
\text { matriculados } \\
\text { por bimestre }\end{array}$ & 29 & 30 & 30 & 31 & 31 \\
\hline $\begin{array}{l}\% \text { de alunos } \\
\text { com nota }<6\end{array}$ & $28,00 \%$ & $26,25 \%$ & $15,50 \%$ & $14,50 \%$ & $7,75 \%$ \\
\hline
\end{tabular}

Revista Educação Online, Rio de Janeiro, n. 25, mai-ago 2017, p. 40-62 


\begin{tabular}{|c|r|r|r|r|r|}
\hline \multicolumn{2}{|c|}{ Média anual 2015 - Utilização da plataforma durante todo o ano letivo } \\
\hline Bimestre & $\begin{array}{l}\text { 10 } \\
\text { Bimestre }\end{array}$ & 20 Bimestre & 3 imestre & 4 - Bimestre & \multicolumn{2}{c|}{$\begin{array}{c}\text { Conceito } \\
\text { Final }\end{array}$} \\
\hline $\begin{array}{c}\text { Quantidade } \\
\text { de alunos } \\
\text { com nota < }\end{array}$ & 3 & 3 & 3 & 8 & 2 \\
\hline $\begin{array}{c}\text { Alunos } \\
\text { matriculados } \\
\text { por bimestre }\end{array}$ & 26 & 26 & 26 & 26 & \\
\hline $\begin{array}{c}\% \text { de alunos } \\
\text { com nota <6 }\end{array}$ & $11,00 \%$ & $9,75 \%$ & $9,75 \%$ & $28,75 \%$ & $6,25 \%$ \\
\hline
\end{tabular}

\subsection{Contribuições da plataforma sob o ponto de vista de alunos e professores de matemática}

Para esta análise, nosso objetivo foi o de investigar se a utilização da plataforma Khan Academy no laboratório de informática contribuiu com 0 aprendizado de matemática, levando em consideração o ponto de vista dos alunos e professores que participaram da pesquisa. Para isso, aplicamos o questionário em 2016, a dois professores de matemática que trabalharam com as turmas de $6^{\circ}$ ano em 2015, e a vinte alunos que cursaram o 6ำ ano em 2015. Elaboramos vinte e quatro questões para cada grupo e, com essas questões, buscamos compreender de que maneira alunos e professores fizeram uso da plataforma, de modo a contribuir para o processo de ensino e aprendizagem.

Figura 1: Participantes da pesquisa

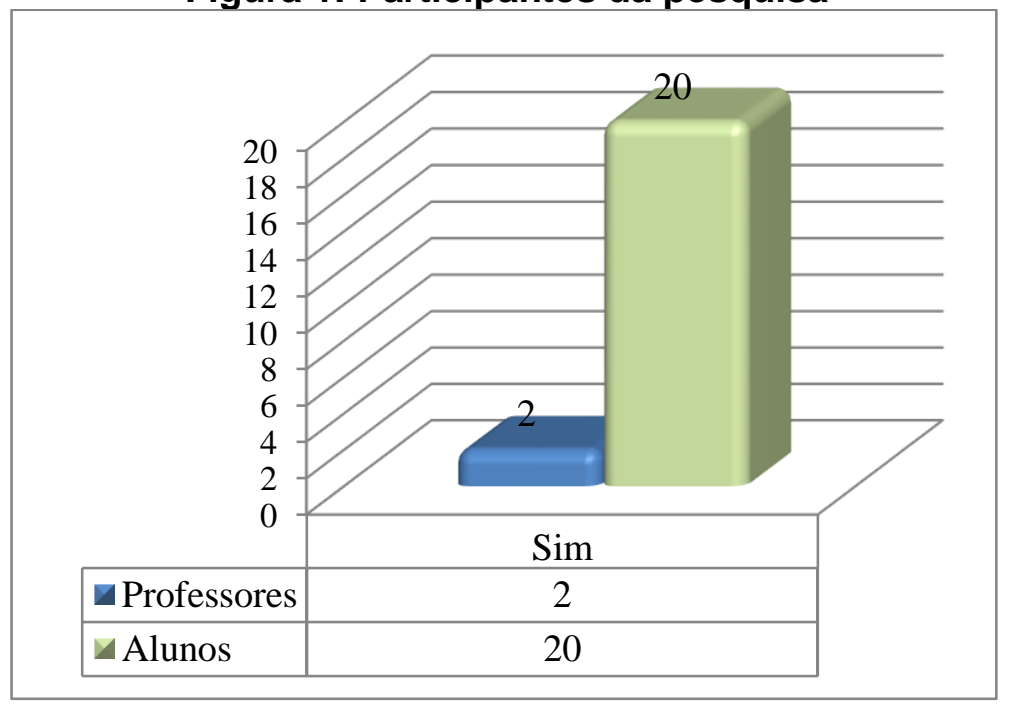

Revista Educação Online, Rio de Janeiro, n. 25, mai-ago 2017, p. 40-62 
A partir daqui, faremos um breve relato sobre o retorno do questionário, apontando alguns itens, através de gráficos, que permitem a análise das respostas.

A Fundação Lemann sugere que escola e professores tenham a disponibilidade de acesso ao uso da plataforma por duas horas aula por semana. Para isso, foram disponibilizados agendamentos ao laboratório de informática, onde o professor de matemática faz o acompanhamento da turma e ministra sua aula, fazendo uso da plataforma. De acordo com os alunos, esse agendamento foi considerado como uma ação importante, pois completa as explicações dadas em sala de aula. O professor incentiva aos alunos a fazerem uso dos recursos oferecidos na plataforma como dicas e vídeos, para melhor compreensão dos exercícios, o que corrobora com Moran (2000), ao alegar que "o papel do educador é o de coordenar, sensibilizar, organizar o processo", que vai sendo construído em conjunto com as habilidades e tecnologias possíveis a cada grupo, de forma participativa. Nesse sentido, ao incentivar seus alunos a utilizarem recursos disponíveis na plataforma, está executando o papel de mediador e contribuindo para que o aluno possa construir seu próprio conhecimento. Para esse autor, essa mediação conduz a um processo baseado na confiança, na comunicação autêntica, na interação, na troca, no estímulo, com normas e limites, mas sempre enfatizando o incentivo, facilitando todo o processo de organização da aprendizagem. 
Figura 2: Opinião dos alunos sobre o acompanhamento do professor de matemática às aulas agendadas no laboratório de informática

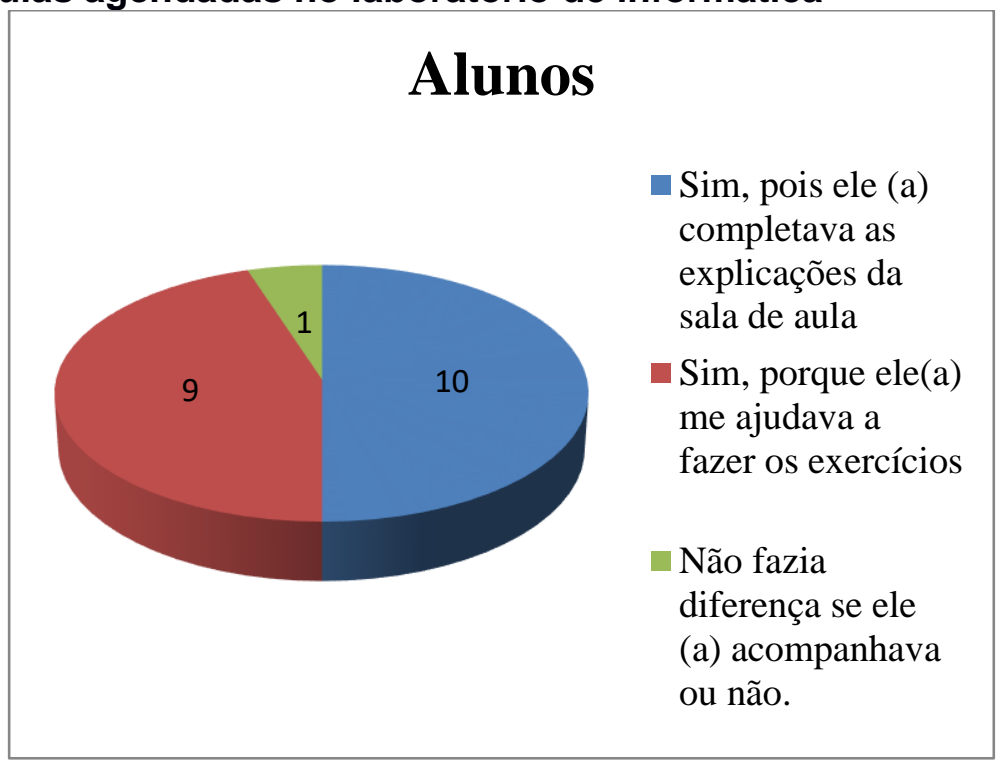

Além disso, os professores mantêm a motivação ao uso durante todo o tempo de aula, pois apresentam os resultados alcançados pela turma por meio dos relatórios disponibilizados na plataforma e incentivam o aluno verificar sua evolução através da ferramenta de progresso. Por meio dessa ferramenta, o próprio aluno percebe seu desempenho, como: tempo de utilização, habilidades dominadas, dificuldades, além da pontuação. Tudo isso pode ser verificado por meio de gráficos, possibilitando ao aluno fazer uma leitura detalhada de sua evolução e permitindo que, além das atividades designadas pela plataforma e pelo professor, ele mesmo possa enviar a si próprio atividades que considera que necessitam de mais atenção, fazendo uso de dicas e vídeos e, consequentemente, mais prática de atividades. Tanto o aluno quanto o professor possuem acesso a essas informações e, ao consultá-las, podem se planejar e estabelecer metas. Devido a isso, alunos e professores confirmam que a plataforma colabora para o aprendizado matemático em sala de aula e promove a melhoria das notas nessa disciplina. 
Figura 3: A plataforma Khan Academy contribuiu para o aprendizado matemático em sala de aula, promovendo a melhoria das notas no componente curricular de matemática?

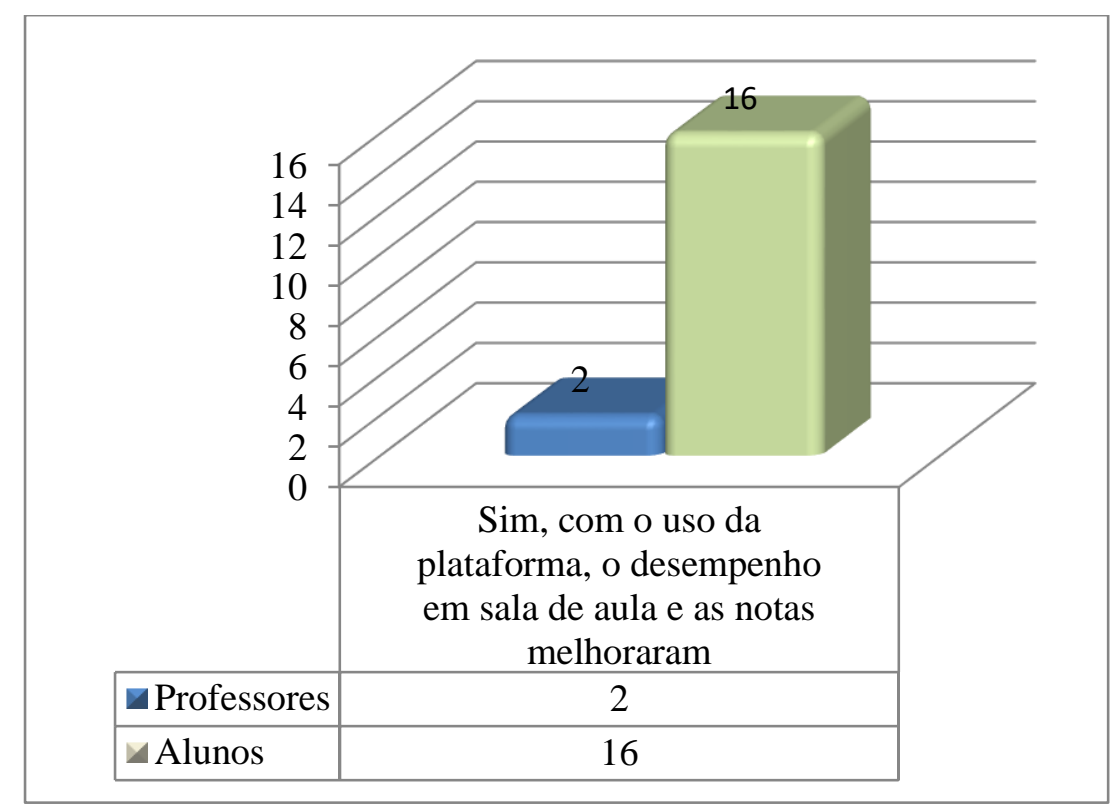

Professores e alunos consideram que fazer uso dos relatórios para realizar uma avaliação diagnóstica do aluno é uma prática válida, pois entendem que a plataforma é capaz de manter o professor informado quanto às habilidades dominadas e às dificuldades que 0 aluno apresenta. Para Luckesi (2005, p. 2), a avaliação deve ser diagnóstica, gerando ao professor um conhecimento sobre o estado de aprendizagem de seu aluno. Assim, tanto é importante o que ele aprendeu, como o que ele ainda não aprendeu e as necessidades de aprendizagem, indicando a necessidade da intervenção para reorientação. Nesse sentido, os relatórios fornecidos pela plataforma possibilitam ao professor realizar esse diagnóstico, essa investigação, na qual, com seu olhar atento, poderá perceber as dificuldades do aluno e os prérequisitos necessários. Esses dados são de importante relevância para as intervenções dos educadores no aprendizado dos alunos.

Revista Educação Online, Rio de Janeiro, n. 25, mai-ago 2017, p. 40-62 
Figura 4: Uso dos dados obtidos por meio dos relatórios da plataforma Khan Academy para utilização como uma das ferramentas de avaliação

Aluno - Sim, pois através dela, o professor pode saber todas as nossas dificuldades e habilidades dominadas e consequentemente considerar como avaliação

Professor - Sim, usei e foi muito prático

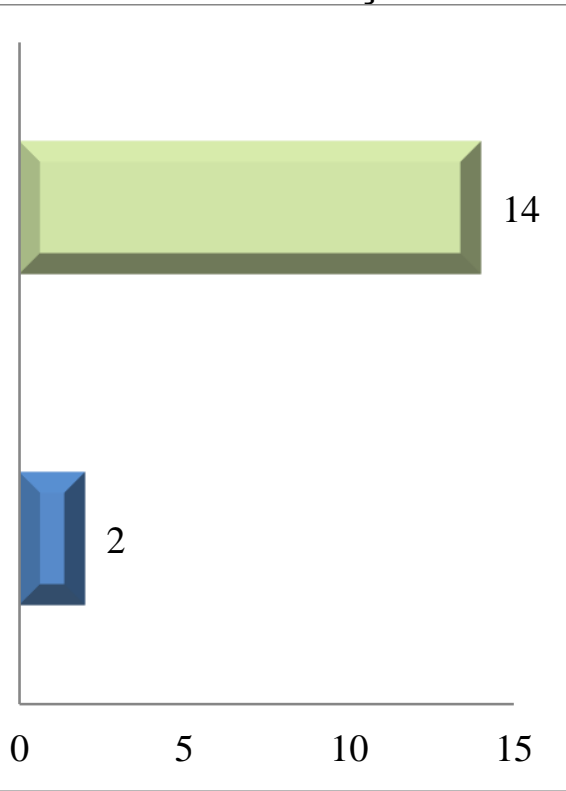

Percebemos que o uso da plataforma fora do laboratório de informática ocorria esporadicamente, não contemplando como positiva a maioria das respostas dos alunos. Então, propusemos uma questão para compreender se, no caso de esse aluno receber uma motivação por meio de rede social como um blog, ele iria acessá-lo e, por conseguinte, iria obter mais motivação para acessar a plataforma fora do horário de aula, incentivando outras pessoas a usarem, o que foi respondido de forma positiva pela maior parte dos entrevistados. 
Figura 5: Consulta a blog para fazer melhor uso da plataforma Khan Academy

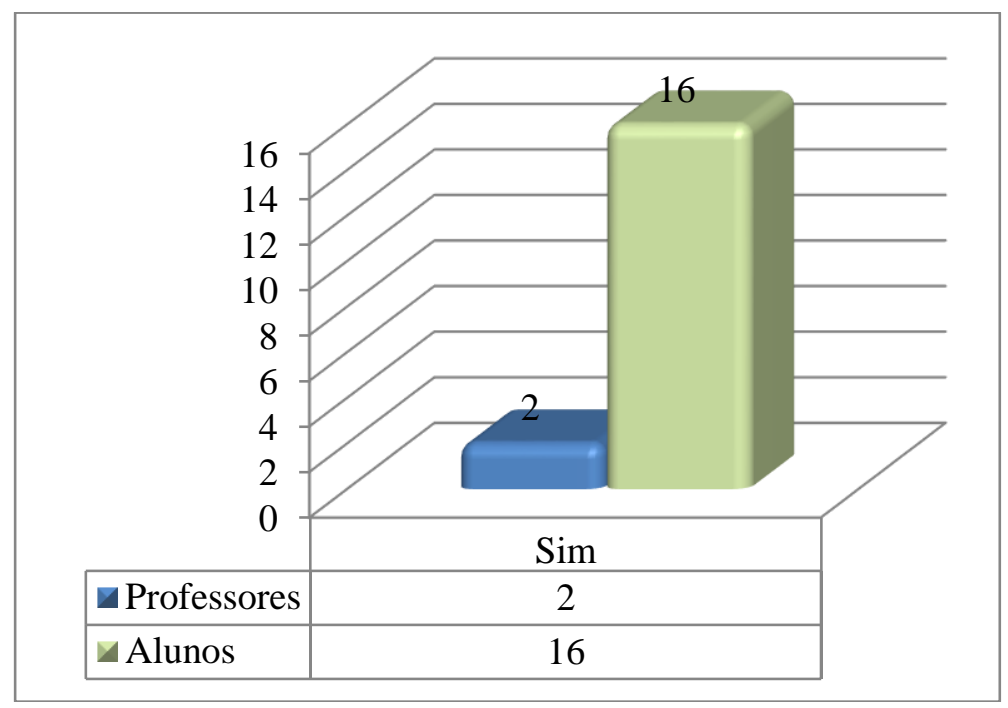

A plataforma Khan Academy, ao permitir ao professor monitorar e identificar o progresso de seus alunos, bem como o tempo gasto em cada atividade praticada, possibilita-Ihe analisar se o aluno está apresentando dificuldade ou se destacando em algum assunto. Permite-lhe gerenciar o progresso e acompanhar de perto o desempenho da aprendizagem de cada aluno. Dessa forma, o professor de matemática pode utilizar recursos tecnológicos como ferramenta facilitadora para diagnóstico e planejamento de suas aulas, tornando-a uma poderosa ferramenta pedagógica. Nesse sentido, podemos afirmar, de acordo com as questões respondidas pelos professores, que o uso da plataforma contribuiu como ferramenta facilitadora para a prática pedagógica em sala de aula.

Revista Educação Online, Rio de Janeiro, n. 25, mai-ago 2017, p. 40-62 
Figura 6: Acompanhamento e análise de relatórios na plataforma Khan Academy e recomendação de exercícios que servissem de pré-requisitos para sanar dificuldades e minimizar dúvidas nas aulas seguintes

\section{Professores}

Sim, fazia uma análise minuciosa de cada aluno para tentar ajudá-lo a sanar as dificuldades preliminares para, depois, recomendar os exercícios que dependessem do domínio daquela habilidade.

Sim, acompanhava os relatórios e com, a análise, me programava para explicar na sala de aula e minimizar os maiores focos de dúvidas. Recomendava atividades para os alunos praticarem na próxima aula, com uso do Khan.

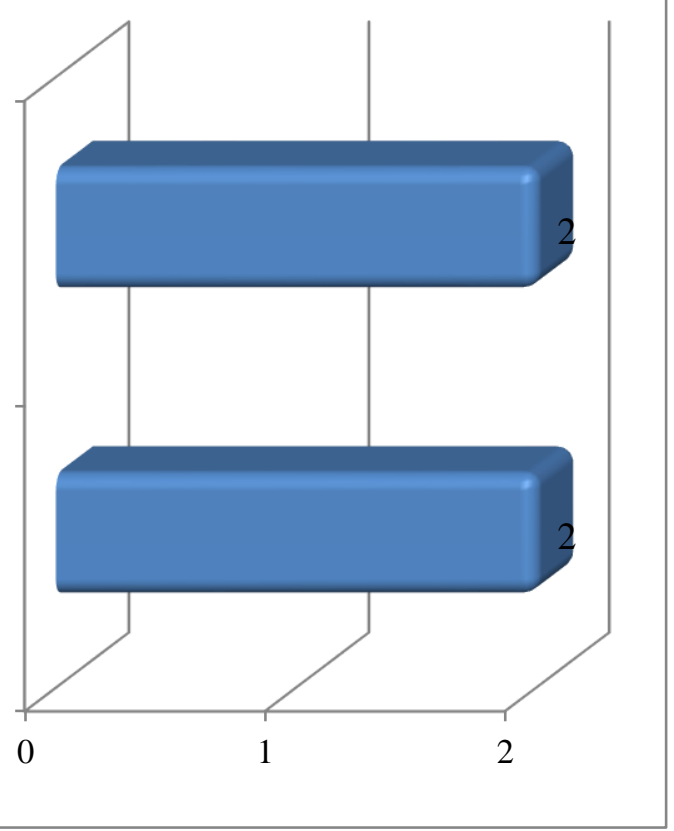

Após análise desses e de outros gráficos, a partir das respostas dos entrevistados, elaboramos nosso produto final, um blog, buscando dar suporte e incentivo ao maior número de pessoas quanto fosse possível, em relação aos recursos disponíveis na plataforma, bem como postagens que promovessem a interação entre alunos, professores, familiares e a quem mais pudesse interessar. Sendo assim, elaboramos a construção de um blog educacional, voltado à utilização, manuseio e divulgação de informações referentes ao uso da plataforma Khan Academy.

De acordo com Araújo (2017) "os blogs tornaram-se o endereço virtual de várias pessoas e empresas, tornando-se fonte de obtenção de informações, ferramenta de trabalho e auxílio de diversos profissionais, especialmente jornalistas, repórteres e professores" (p. 1).

Nesse sentido, Kensky (2015, p. 44-48) afirma que a presença de uma determinada tecnologia pode induzir profundas mudanças na maneira de 
organizar o ensino, podendo alterar profundamente a natureza do processo educacional e a comunicação entre os participantes. Com isso, possibilita-se provocar a alteração dos comportamentos de professores e alunos, levando-os ao melhor conhecimento e maior aprofundamento do conteúdo estudado.

\section{Considerações finais}

O presente estudo permitiu analisar se uso da plataforma Khan Academy contribui como ferramenta facilitadora de suporte ao aprendizado de matemática, com aulas ministradas no laboratório de informática.

Ao fazermos análise das notas disponibilizadas no Siges, entendemos que a utilização dessa plataforma na escola pesquisada trouxe uma contribuição significativa à evolução da aprendizagem do conteúdo matemático referente ao período analisado. Pudemos perceber que, com o crescente uso da plataforma, houve considerável evolução.

Antes do uso da plataforma, havia um alto índice de notas inferiores a seis, abaixo do conceito satisfatório adotado pela Secretaria da Educação de Santos. Acreditamos que vários fatores puderam contribuir para essa melhoria. Pelas respostas disponibilizadas nos questionários, professores e alunos envolvidos consideram que a plataforma foi fundamental para que ocorresse tal evolução. Nesse sentido, entendemos que para atender a alunos, atualmente denominados nativos digitais, proporcionando uma aprendizagem mais ativa (MENEGAIS, 2015), o professor deve desempenhar o papel de agente provocador do desequilíbrio cognitivo dos alunos, envolvendo-os e centralizando-os no processo de aprendizagem.

Assim, a utilização da plataforma Khan Academy, na escola pesquisada, trouxe contribuição significativa, no que diz respeito à evolução e aprendizagem do conteúdo matemático, referente ao período de 2013 a 2015, atingindo o objetivo proposto, de avaliar por meio do levantamento de notas bimestrais da disciplina de matemática, se o uso da plataforma Khan Academy contribuiu de maneira efetiva para a melhora do desempenho matemático de alunos do sexto ano do ensino fundamental.

Revista Educação Online, Rio de Janeiro, n. 25, mai-ago 2017, p. 40-62 
Ao utilizar recursos tecnológicos que proporcionam ao aluno práticas pedagógicas ativas, desencadeamos aprendizagem em espaço pedagógico tecnológico, para que se promova a construção do conhecimento efetivo. Ao permitir ao aluno aprender dentro do seu próprio ritmo, ajustando os conteúdos às suas necessidades e ao nível de desenvolvimento, estamos possibilitando a ele minimizar suas dificuldades quanto às crenças, atitudes, expectativas e fatores emocionais acerca da matemática (SANCHEZ, 2004). Nesse sentido, esse aluno descobre, constrói e modifica, de forma criativa, seu próprio conhecimento; e, por meio da plataforma, ao acessar o perfil do usuário, pode observar e analisar dados estatísticos que demonstram exatamente o que foi praticado. Os alunos consideram uma ação estimulante ao acompanhamento da sua evolução, ou seja, percebem os progressos de aprendizagem nos conteúdos matemáticos.

Analisando ainda de que maneira a plataforma teve contribuição efetiva para o aprendizado matemático do aluno, podemos considerar também que os avatares disponibilizados por ela são estratégias relevantes e de incentivo ao uso e, consequentemente, ao aprendizado matemático, pois, ao disponibilizar como forma de recompensa a possibilidade de se adquirir pontos e a troca desses pontos pela imagem de avatares, o aluno disponibiliza em seu perfil o grau de pontuação atingido. Isso faz com que a competitividade entre eles seja mais acirrada, e só ocorrerá evolução e ganho de pontos, se houver domínio de habilidades. Nesse caso, a competitividade se torna um fator positivo, pois contribui para o seu aprendizado.

O gerenciamento possibilitado por meio dos relatórios disponibilizados na plataforma permite ao professor acompanhar o desempenho de seus alunos, bem como realizar a programação de suas próximas aulas. Os diagnósticos que os relatórios fornecem ao professor, se forem bem utilizados e interpretados, podem tornar-se uma poderosa ferramenta pedagógica, favorecendo tanto o ensino quanto a aprendizagem. 


\section{Referências bibliográficas}

ACADEMY KHAN. Disponível em:<www.khanacademy.org.br>. Acesso em: 10 jun. 2015.

ARAÚJO, C. O que são blogs? Disponível em:

<http://www.infoescola.com/informatica/o-que-sao-blogs/> Acesso em: 01 mai. 2017.

COLL, C.; MONEREO, C. Psicologia da educação virtual: aprender e ensinar com as tecnologias da informação e da comunicação. Porto Alegre: Artmed, 2010.

FUNDAÇÃO LEMANN. Quem somos. Disponível em: <http://www.fundacaolemann.org.br/quem-somos/>. Acesso em: $01 \mathrm{dez} .2015$. Disponível em:

<http://fundacaolemann.org.br/khanportugues/\#o-programa>. Acesso em: 10 jun. 2015.

KENSKI, Vani Moreira. Educação e tecnologia: o novo ritmo da informação. Campinas, SP: Papirus, 2015. (Coleção Educação). Disponível em: <http://signorelli.bv3.digitalpages.com.br/users/publications/9788530811549/pa ges/45>. Acesso em: 02 nov. 2016.

LUCKESI, Cipriano Carlos. Avaliação da aprendizagem escolar: estudos e proposições. 17ª̂ed. São Paulo: Cortez Editora, 2005.

Disponível em:

Avaliação da aprendizagem... mais uma vez.

<http://www.luckesi.com.br/textos/abc_educatio/abceducatio_46_avaliacao_da

_aprendizagem_mais_uma_vez.pdf> Acesso em: 16 mai. 2016.

MEDEIROS FILHO, Dante Alves; MOURA, Ernani Guilherme Groff. A metodologia de ensino da Khan Academy para a área tecnológica. Disponível em:

<http://www.espweb.uem.br/site/files/tcc/2011/Ernani\%20Guilherme\%20Groff\% 20Moura\%20-

$\% 20 \mathrm{~A} \% 20$ metodologia\%20de\%20ensino\%20da\%20Khan\%20Academy\%20par a\%20a\%20area\%20tecnologica.pdf> Acesso em: 14 jul. 2016.

MENEGAIS, D. A. F. N. A formação continuada de professores de matemática: uma inserção tecnológica da plataforma Khan Academy na prática docente. Tese. (Doutorado em Informática na Educação) - Universidade Federal do Rio Grande do Sul. Porto Alegre, 2015. Disponível em: <http://www.lume.ufrgs.br/bitstream/handle/10183/122036/000967725.pdf?sequ ence $=1>$. Acesso em: 25 set. 2015.

MENEGAIS, D. A. F. N.; FAGUNDES, L. da C.; SAUER, L. Z. Impacto da inserção de tecnologias digitais na formação inicial de professores de matemática egressos de uma universidade pública federal. RENOTE Revistas Novas Tecnologias na Educação, v.12, n. 2, s/p, jul 2014. Disponível 
em: <http://seer.ufrgs.br/index.php/renote/article/view/53560> Acesso em: 25 set. 2015.

MORAN, José Manuel. Mudar a forma de aprender e ensinar com tecnologias. In: Revista Interações, v. 5, n. 9, p. 57-72, jan-jun 2000. Disponível em:<http://www.redalyc.org/pdf/354/35450905.pdf >. Acesso em: 24 jan. 2017.

PERRENOUD, P. Dez novas competências para ensinar. Porto Alegre: Artmed, 2000.

PIAGET, J. Seis estudos de psicologia. Rio de Janeiro. Forense, 1964.

. Estudos sociológicos. Rio de Janeiro. Forense, 1973.

. Epistemologia genética. 2ed. São Paulo: Martins Fontes, 2002.

PINHEIRO, C. D. B.; LEAL. S. D. A.; LIMA. C. P. Um cenário viável para motivar os alunos do ensino fundamental para um futuro ingresso nos cursos superiores de computação. Disponível em: <http://brie.org/pub/index.php/wie/article/view/5064> Acesso em: 14 jul. 2016.

SANCHEZ, J. N. G. Dificuldades de aprendizagem e intervenção psicopedagógica. Porto Alegre: Artmed, 2004.

TAVARES, Wellington; PAULA, H. C.; LIMA, M. A.; BARBOSA, F. V. Khan Academy: uma abordagem da escola tradicional da educação? In: RENOTE Revista Novas Tecnologias na Educação. v. 10 n. 1, s/p, jul 2012. Disponível em: < http://seer.ufrgs.br/renote/article/view/30852> Acesso em: 25 set. 2015. 